\section{FRI0252 SUMMARY OF NEUTROPENIA IN PATIENTS WITH RHEUMATOID ARTHRITIS TREATED WITH SIRUKUMAB IN THE SIRROUND PHASE 3 CLINICAL TRIALS}

T. Takeuchi ${ }^{1}$, Y. Tanaka ${ }^{2}$, M. Schiff ${ }^{3}$, M. Harigai ${ }^{4}$, K. Brown ${ }^{5}$, R. Rao ${ }^{6}$, K. Fei $^{7}$ S. Popik ${ }^{7}$, K. Yoshizawa ${ }^{8}$, Q. Wang ${ }^{7}$, B. Hsu ${ }^{7} .{ }^{1}$ Division of Rheumatology, Keio University School of Medicine, Tokyo; ${ }^{2}$ University of Occupational and Environmental Health, Kitakyushu, Japan; ${ }^{3}$ University of Colorado School of Medicine, Denver, CO, United States: ${ }^{4}$ Tokyo Women's Medical University, Shinjuku-ku, Tokyo, Japan; ${ }^{5}$ GlaxoSmithKline, Collegeville, PA, United States; ${ }^{6}$ GSK Medicines Research Centre, Hertfordshire, United Kingdom; ${ }^{7}$ Janssen Research \& Development, LLC, Spring House, PA, United States; ${ }^{8}$ Janssen Pharm KK Japan, Chiyoda-ku, Tokyo, Japan

Background: Neutropenia has been reported with interleukin-6 (IL-6) pathway inhibitors and could potentially be associated with increased rates of infection. The reduced neutrophil counts seen with IL-6 inhibitors may be due to effects on margination of circulating neutrophils as opposed to a decrease in bone marrow production or reduced survival. Efficacy of sirukumab (SIR), a human anti-IL-6 cytokine monoclonal antibody, has recently been shown in several phase 3 trials. Objectives: To assess incidence of neutropenia from completed and ongoing SIRROUND clinical studies.

Methods: Neutrophil counts were compared for SIR 50mg q4w and 100mg q2w doses vs placebo (pbo) in the pbo-controlled period (Wks $0-18$ ) of 2 phase 3 trials and in long-term analysis for the 5 -trial, phase 3 program.

Results: 2926 pts received SIR for up to $3.4 y$ with a median duration of $1.46 \mathrm{y}$. For the 18-wk pbo-controlled period, neutropenia was more frequent in both SIR groups compared with pbo. Across all groups, the majority of the decreases in neutrophil counts were National Cancer Institute Common Terminology Criteria for Adverse Events grade 0/1, within the normal range, and the incidence of grade $3 / 4$ decreases was low across groups (Table). Neutropenia began at Wk 2 and persisted through the study period. In long-term analysis, the proportions of pts with grade 1,2 , or 3 neutropenia were slightly higher than in the 18-wk pbo-controlled period, suggesting the majority of events occurred early. No dose relationship was observed in the grade or frequency of neutropenia. Grade $3 / 4$ neutropenia was mostly transient and resolved after interrupting the dose or resolved within the dosing interval such that no change in dose schedule was required. The majority of grade 4 decreases in neutrophils were not correlated with infections; 2 cases of serious infections occurred with grade 4 neutropenia. The distribution of neutropenia by grade was similar in pts who did or did not use disease-modifying antirheumatic drugs (DMARDs) at baseline.

Table 1. Neutropenia by Maximum Toxicity Grade Across Phase 3 Trials (n, \%)

\begin{tabular}{|c|c|c|c|c|c|}
\hline \multirow[t]{2}{*}{ Neutrophil count decreased } & \multicolumn{3}{|c|}{$0-18$ wks } & \multicolumn{2}{|c|}{ Long-term analysis } \\
\hline & $\begin{array}{c}\text { Pbo } \\
(\mathrm{N}=850)\end{array}$ & $\begin{array}{c}\text { SIR } \\
50 \mathrm{mg} \mathrm{q} 4 \mathrm{w} \\
(\mathrm{N}=848)\end{array}$ & $\begin{array}{c}\text { SIR } \\
100 \mathrm{mg} \text { q2w } \\
(\mathrm{N}=850)\end{array}$ & $\begin{array}{c}\text { SIR } \\
50 \mathrm{mg} \mathrm{q} 4 \mathrm{w} \\
(\mathrm{N}=1454)\end{array}$ & $\begin{array}{c}\text { SIR } \\
100 \mathrm{mg} \text { q2w } \\
(\mathrm{N}=1461)\end{array}$ \\
\hline Grade & $816(96.9)$ & $576(68.3)$ & $568(67.1)$ & $843(58.0)$ & $806(55.2)$ \\
\hline Grade $1(3)$ & $19(2.3)$ & $149(17.7)$ & $167(19.7)$ & $313(21.5)$ & $352(24.1)$ \\
\hline Grade $2\left(<1,500-1,000 / \mathrm{mm}^{3}\right)$ & $5(0.6)$ & $97(11.5)$ & $94(11.1)$ & $222(15.3)$ & $240(16.4)$ \\
\hline Grade $3\left(<1,000-500 / \mathrm{mm}^{3}\right)$ & $1(0.1)$ & $21(2.5)$ & $16(1.9)$ & $68(4.7)$ & $61(4.2)$ \\
\hline Grade $4\left(<500 / \mathrm{mm}^{3}\right)$ & $1(0.1)$ & 0 & $1(0.1)$ & $8(0.6)$ & $2(0.1)$ \\
\hline
\end{tabular}

LLN, lower limit of normal.

Conclusions: Across phase 3 studies, there was no dose effect of SIR on neutropenia, and the use of DMARDs did not have an apparent effect on neutropenia. The majority of grade 4 neutropenia with SIR was not associated with infections.

Disclosure of Interest: T. Takeuchi Grant/research support from: Astellas Pharma, Bristol-Myers K.K., Chugai Pharmaceutical Co., Ltd., Daiichi Sankyo Co., Ltd., Eisai Co., Ltd., Mitsubishi Tanabe Pharma Co., Pfizer Japan Inc., Santen Pharmaceutical Co., Ltd., Takeda Pharmaceutical Co., Ltd., Teijin Pharma Ltd., AbbVie GK, Asahi Kasei Pharma Corp., Taisho Toyama Pharmaceutical Co., Ltd., and SymBio Pharmaceuticals Ltd, Consultant for: Astra Zeneca K.K., Eli Lilly Japan K.K., Novartis Pharma K.K., Mitsubishi Tanabe Pharma Co., Asahi Kasei Medical K.K., AbbVie GK, Daiichi Sankyo Co., Ltd., Bristol-Myers K.K., and Nipponkayaku Co. Ltd., Speakers bureau: AbbVie GK., Bristol-Myers K.K., Chugai Pharmaceutical Co., Ltd., Eisai Co., Ltd., Janssen Pharmaceutical K.K., Mitsubishi Tanabe Pharma Co., Pfizer Japan Inc., Takeda Pharmaceutical Co., Ltd., Astellas Pharma, Daiichi Sankyo Co., Ltd., Celtrion, and Nipponkayaku Co. Ltd., Y. Tanaka Grant/research support from: Mitsubishi-Tanabe, Takeda, DaiichiSankyo, Chugai, Bristol-Myers, MSD, Astellas, Abbvie, and Eisai, Speakers bureau: Abbvie, Chugai, Daiichi-Sankyo, Bristol-Myers, Mitsubishi-Tanabe, Astellas, Takeda, Pfizer, Teijin, Asahi-kasei, YL Biologics, Sanofi, Janssen, Eli Lilly, and GlaxoSmithKline, M. Schiff Consultant for: AbbVie, Bristol-Myers Squibb, Eli Lilly, Johnson \& Johnson, UCB, Speakers bureau: AbbVie, M. Harigai Grant/research support from: AbbVie Japan, Astellas Pharma, Bristol-Myers Squibb, Chugai Pharmaceutical, Eisai, Mitsubishi Tanabe Pharma, Ono Pharmaceuticals, Santen Pharmaceutical, Takeda Pharmaceutical, UCB Japan, Teijin Pharma, Consultant for: AbbVie Japan, Janssen Pharma, Chugai Pharmaceutical, Teijin Pharma, Eli Lilly Japan, and Zenyaku Kogyo, K. Brown Shareholder of: GlaxoSmithKline, Employee of: GlaxoSmithKline, R. Rao Shareholder of: GlaxoSmithKline, Employee of: GlaxoSmithKline, K. Fei Shareholder of: Janssen Research \& Development, LLC, Employee of: Janssen Research \& Development, LLC, S. Popik Shareholder of: Janssen Research \& Development, LLC, Employee of: Janssen Research \& Development, LLC, K. Yoshizawa Shareholder of: Janssen Research \& Development, LLC, Employee of: Janssen Research \& Development, LLC, Q. Wang Shareholder of: Janssen Research \& Development, LLC, Employee of: Janssen Research \& Development, LLC, B. Hsu Shareholder of: Janssen Research \& Development, LLC, Employee of: Janssen Research \& Development, LLC DOI: 10.1136/annrheumdis-2017-eular.6413

\section{FRI0253 PATIENT-REPORTED OUTCOMES IN PATIENTS WITH RHEUMATOID ARTHRITIS TREATED WITH SUBCUTANEOUS TOCILIZUMAB COMPARED WITH PLACEBO OR INTRAVENOUS TOCILIZUMAB IN COMBINATION WITH CSDMARDS}

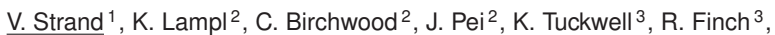
A. Kivitz ${ }^{4}$, G. Burmester ${ }^{5} .{ }^{1}$ Stanford University School of Medicine, Palo Alto; ${ }^{2}$ Genentech, Inc, South San Francisco, United States; ${ }^{3}$ Roche, Welwyn Garden City, United Kingdom; ${ }^{4}$ Altoona Center for Clinical Research, Duncansville, United States; ${ }^{5}$ Charité-Universitätsmedizin Berlin, Free University and Humboldt University of Berlin, Berlin, Germany

Background: Two previous randomized, controlled trials (RCTs), BREVACTA and SUMMACTA, showed subcutaneous tocilizumab (TCZ-SC) was superior to placebo (PBO) and comparable to intravenous TCZ (TCZ-IV) in combination with csDMARDs for improving RA disease activity. ${ }^{1,2}$

Objectives: To compare the efficacy of TCZ-SC with PBO or TCZ-IV + csDMARDs for improvement in patient-reported outcomes (PROs) in 2 RCT populations.

Methods: Both RCTs enrolled patients (pts) with inadequate responses to DMARDs; up to $20 \%$ had inadequate responses to tumor necrosis factor inhibitors. In BREVACTA, pts received blinded TCZ-SC $162 \mathrm{mg}$ or PBO every 2 weeks (q2w) + csDMARDs for 24 weeks. In SUMMACTA, pts received TCZ-SC $162 \mathrm{mg}$ weekly or TCZ-IV $8 \mathrm{mg} / \mathrm{kg}$ q4w + csDMARDs for the 24-week double-blind period. PROs, assessed at 12 weeks (prior to rescue) in BREVACTA and 24 weeks in SUMMACTA, included patient global assessment (PtGA; visual analog score [VAS], 0-100 mm), pain (VAS), Health Assessment Questionnaire Disability Index (HAQ-DI, 0-3) and Short Form-36 (SF-36) physical and mental component summary (PCS, MCS: 0-50) and domain (0-100) scores. The proportions of pts reporting scores $\geq$ minimum clinically important differences (MCID) and $\geq$ age/gender-matched normative values were assessed for each treatment group. Results: Baseline PRO scores were mostly comparable between treatment groups in each study and between study populations. In BREVACTA, significantly more pts who received TCZ-SC reported scores $>$ MCID for all PROs at week 12 compared with PBO (54\% to $73 \%$ vs $42 \%$ to $55 \%$, respectively; number needed to treat [NNT], 5.2 to 13.0 ). Compared with $1 \%$ to $20 \%$ at baseline, $8 \%$ to $34 \%$ of pts who received TCZ-SC and $4 \%$ to $25 \%$ of PBO pts reported scores $\geq$ normative values in all PROs at week 12 (Table). In SUMMACTA, similar proportions of pts who received TCZ-SC and TCZ-IV reported scores $\geq$ MCID in all PROs at week $24(61 \%$ to $84 \%$ vs $64 \%$ to $84 \%$, respectively). The proportion of patients who reported scores $\geq$ normative values was comparable between the TCZ-SC and TCZ-IV groups across all PROs; compared with $0.2 \%$ to $23 \%$ at baseline, $14 \%$ to $41 \%$ of pts who received TCZ-SC and $15 \%$ to $42 \%$ of pts who received TCZ-IV reported scores $\geq$ normative values at week 24 (Table).

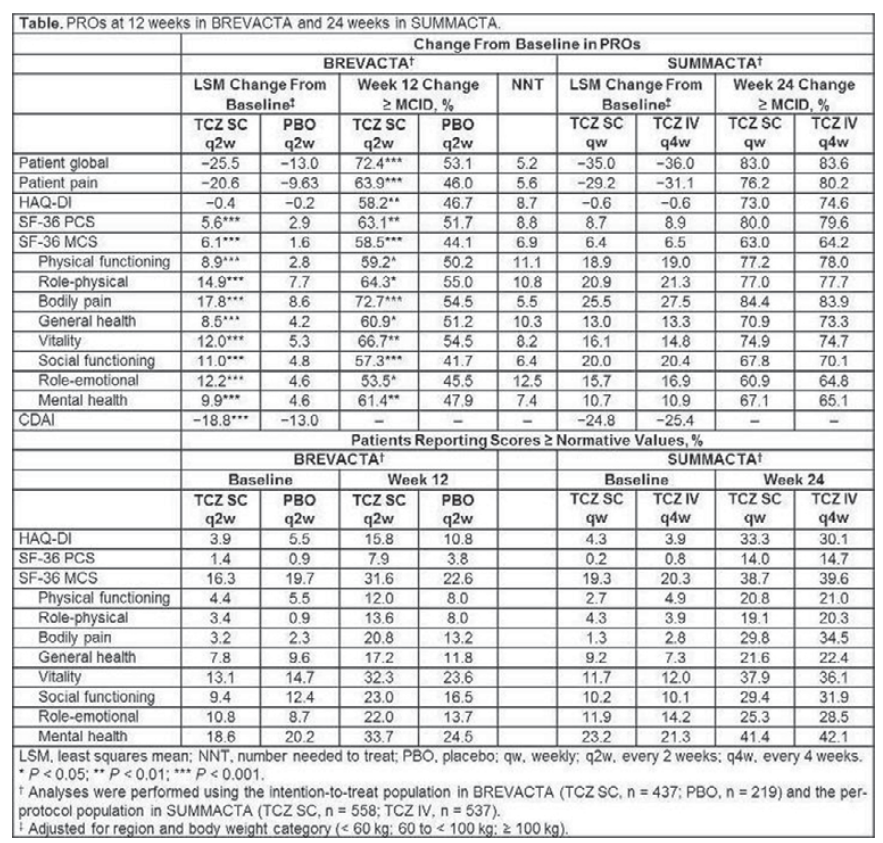

Conclusions: In BREVACTA, TCZ-SC + csDMARDs resulted in significantly greater improvements across all PROs and significantly more pts reporting scores 